\title{
Prevalence of intimate partner violence and abuse and associated factors among women enrolled into a cluster randomised trial in northwestern Tanzania
}

Saidi Kapiga ${ }^{1,2^{*}}$, Sheila Harvey ${ }^{1,3}$, Abdul Khalie Muhammad ${ }^{1}$, Heidi Stöckl ${ }^{3}$, Gerry Mshana ${ }^{1,4}$, Ramadhan Hashim , Christian Hansen ${ }^{1,2}$, Shelley Lees ${ }^{3}$ and Charlotte Watts ${ }^{3}$

\begin{abstract}
Background: Intimate partner violence (IPV) is recognised as an important public health and social problem, with far reaching consequences for women's physical and emotional health and social well-being. Furthermore, controlling behaviour by a partner has a similar impact on women's well-being, yet little is known about the prevalence of this type of behaviour and other related abuses in Tanzania and in other sub-Saharan African countries.
\end{abstract}

Methods: We conducted a cross-sectional study to determine the lifetime and past 12-month prevalence of physical and sexual IPV, economic abuse, emotional abuse and controlling behaviour among ever-partnered women in Mwanza, Tanzania. Women ( $N=1049)$ were enrolled in an ongoing trial (Maisha study) to assess the impact of microfinance combined with gender training on participants' experience IPV, and other related outcomes. Interviews were conducted by same sex interviewers to collect information about socio-demographic characteristics, experiences of specific acts of IPV and abuse, and symptoms of poor mental health status.

Results: Overall, about $61 \%$ of women reported ever experiencing physical and/or sexual IPV (95\% Cl: 58-64\%) and 27\% (95\% Cl: 24-29\%) experienced it in the past 12 months. Partner controlling behaviour was the most prevalent type of abuse with $82 \%$ experiencing it in their lifetime and $63 \%$ during the past 12 months. Other types of abuses were also common, with 34\% of women reporting economic abuse and 39\% reporting emotional abuse during the past 12 months. The prevalence of IPV and abuses varied by socio-demographic characteristics, showing much higher prevalence rates among younger women, women with young partners and less educated women. After we adjusted for age and socio-economic status, physical violence $(\mathrm{OR}=1.8 ; 95 \% \mathrm{Cl}$ : 1.3-2.7) and sexual violence $(\mathrm{OR}=2.8 ; 95 \% \mathrm{Cl}: 1.9-4.1)$ were associated with increased reporting of symptoms of poor mental health. Similarly, experience of abuse during the past 12 months was associated with increased reporting of symptoms of poor mental health.

Conclusions: The high prevalence of IPV and abuses and its strong links with symptoms of poor mental health underline the urgent need for developing and testing appropriate interventions in settings like Tanzania to tackle both violence and abusive behaviours among intimate partners.

(Continued on next page)

\footnotetext{
* Correspondence: Saidi.Kapiga@lshtm.ac.uk

${ }^{1}$ Mwanza Intervention Trials Unit, PO Box 11936, Mwanza, Tanzania

${ }^{2}$ Department of Infectious Diseases Epidemiology, London School of Hygiene

\& Tropical Medicine, Keppel Street, London WC1E 7HT, UK

Full list of author information is available at the end of the article
} 
(Continued from previous page)

Trial registration: ClinicalTrials.gov - ID NCT02592252, registered retrospectively on 13 August 2015.

Keywords: Intimate partner violence, Economic abuse, Emotional abuse, Controlling behaviour, Mental health, Intervention, Cross-sectional study, Women, Tanzania, Africa

\section{Background}

Intimate partner violence (IPV) is recognised as an important public health problem, development issue and human rights concern. Globally, it is estimated that about $30 \%$ of women will experience physical and/or sexual violence from an intimate partner during their lifetime [1], and that one in three homicides among women are by an intimate partner [2]. Lifetime rates of physical and/or sexual IPV have been found to be highest in south-East Asia, the Mediterranean region and sub-Saharan Africa [1]. In Tanzania, almost 2 in 5 women aged 15 to 49 years have experienced physical violence at some point in their lives, $44 \%$ of ever-married women have experienced physical and/or sexual violence by their current or most recent husband or partner, and $37 \%$ of ever-married women experienced such spousal violence in the past 12 months [3]. Results from the baseline survey of an ongoing clusterrandomized HIV and gender-based violence prevention trial in Dar es Salaam, Tanzania showed that within the last 12 months, $35.8 \%$ of women reported experiencing physical, sexual and/or psychological IPV [4].

Experience of IPV has far reaching consequences for women's physical and emotional health and social wellbeing [5-7]. Women who experience IPV show more physical symptoms of poor health, and more days out of work and injuries than women who have not been abused $[5,7]$. IPV has also been associated with mental health problems, including depression, anxiety, phobias, posttraumatic stress disorder, suicide, and alcohol and drug abuse [6-10]. Furthermore, recent evidence suggests that controlling behaviour by a partner has a similar impact on women's well-being [11], yet little is known about the prevalence of this type of behaviour and other related abuses in Tanzania.

Several intervention studies have been implemented in low and middle income countries to address IPV [12-15]. One example is the Intervention with Microfinance for AIDS and Gender Equity (IMAGE) trial implemented in rural South Africa [13], which found that a gender empowerment intervention linked to microfinance loans was associated with $55 \%$ reduced IPV incidence in the past year. We are currently conducting a trial (MAISHA study), to adapt and evaluate the impact of the IMAGE model in Mwanza city, northwestern Tanzania.

In this paper, we describe the design of the MAISHA study and present the baseline lifetime and past 12-month prevalence and severity of physical and sexual IPV and other abuses, including economic abuse, emotional abuse and controlling behaviour. Additionally, we assessed the co-occurrence (or overlap) of different forms of violence and abuses, and the associations between experience of violence and abuses, and socio-demographic characteristics and women's self-reported mental health status.

\section{Methods}

\section{MAISHA study design and procedures}

MAISHA study is a cluster-randomised controlled trial to assess the impact of a combined microfinance and gender training programme for women on participants' experience of physical and/or sexual violence, as well as other gender-empowerment, economic, and health related outcomes. The trial is a collaboration with an established local microfinance provider in Tanzania (Bangladesh Rural Advancement Committee or BRAC). As part of BRAC microfinance programme standard procedures, loans are provided to women in groups, with about 10-30 women per group. We recruited into the trial 66 existing BRAC microfinance loan groups from low socio-economic communities in Mwanza city. Each woman in the groups approached for this study met with a staff member to go through the participant information sheet and those who agreed to participate and demonstrated understanding of the study procedures were invited to sign the consent form. Following completion of baseline data collection, loan groups were randomly allocated in a 1:1 ratio to either continue with microfinance only ( $N=33$ groups) or to receive a combined microfinance and gender training intervention ( $N=33$ groups). The gender training intervention included 10 sessions delivered by female facilitators over 20 weeks at a venue convenient to the participants. The training was developed drawing on six curricula including the Sisters For Life curriculum originally developed for the IMAGE trial [13].

\section{Baseline survey}

During the baseline survey, consenting women were interviewed, face-to-face, using a structured questionnaire, with responses entered directly onto a tablet computer programmed to check for accuracy and consistency of information entered during the interview. Interviews were conducted in a private location by female interviewers trained on interviewing techniques, gender issues, violence, and ethical issues related to research on IPV. We used a standardised structured questionnaire which was 
translated into a local language (Swahili) and then independently back-translated into English to check for accuracy. The questionnaire included information about household details, income, relationships, health, childhood and experiences of specific acts of IPV and abuse. Symptoms of poor mental health were assessed using a standardised tool (SRQ-20), integrated into the health section of the questionnaire, which was developed by WHO [16] and has been validated in a range of populations [17]. Questions asking about each type of violence and abuse were adapted from the WHO Violence Against Women instrument (Table 1) [18].

In order to ensure support for participants who reported acts of violence or abuse perpetrated against them, we identified service providers in the communities where we recruited study participants. Our study team met with representatives of each service provider to inform them about the study and to establish effective mechanisms for referring women for ongoing help and support.

\section{Data analysis}

Intimate partner violence was defined as one or more acts of physical and/or sexual violence and abuse was defined as one or more acts of either controlling behaviour, emotional abuse and/or economic abuse (Table 1). We defined the prevalence of ever experiencing IPV as the proportion of ever-partnered women (i.e. women who had ever been in a relationship including those who had ever been married or lived with a partner) reporting one or more acts of physical and/or sexual violence by an intimate partner at any point in their lives. Current prevalence of IPV was defined as the proportion of everpartnered women reporting one or more acts of violence during the 12 months before the interview. The same

Table 1 Questions used in the study to document violence, controlling behaviours, emotional abuse and economic abuse by an intimate partner in Mwanza, Tanzania

\begin{tabular}{|c|c|}
\hline & Questions \\
\hline \multirow[t]{7}{*}{ Physical violence } & Has your current partner or any other partner ever... \\
\hline & 1. Slapped you or thrown something at you that could hurt you? \\
\hline & 2. Pushed you or shoved you or pulled your hair? \\
\hline & 3. Hit you with his fist or with something else that could hurt you? \\
\hline & 4. Kicked you, dragged you or beaten you up? \\
\hline & 5. Choked or burnt you on purpose? \\
\hline & 6. Threatened to use or actually used a gun, knife or other weapon against you? \\
\hline \multirow[t]{4}{*}{ Sexual violence } & Have you ever had sexual intercourse with your current partner or other partner \\
\hline & 1. After he forced you by threatening you, holding you down or hurting you in some way? \\
\hline & $\begin{array}{l}\text { 2. When you did not want to because you were afraid that your partner would hurt you or someone you } \\
\text { cared about if you refused? }\end{array}$ \\
\hline & $\begin{array}{l}\text { 3. When you did not want to because you were afraid that your partner would leave you or take another } \\
\text { girlfriend if you refused? }\end{array}$ \\
\hline \multirow[t]{6}{*}{ Controlling behaviours } & Thinking about your (current or most recent or past) partner, would you say it is generally true that he: \\
\hline & 1. Tries to keep you from seeing your friends \\
\hline & 2. Tries to restrict contact with your family of birth \\
\hline & 3. Insists on knowing where you are at all times \\
\hline & 4. Is jealous and gets angry if you speak with another man \\
\hline & 5. Is often suspicious that you are unfaithful \\
\hline \multirow[t]{4}{*}{ Economic abuse } & Thinking about your (current or most recent/past) partner, would you say it is generally true that he: \\
\hline & 1. Refuses to give you enough money for household expenses, even when he has money for other things? \\
\hline & 2. Takes money that you have earned away from you \\
\hline & 3. Makes important financial decisions without consulting you \\
\hline \multirow[t]{5}{*}{ Emotional abuse } & Has your current partner, or any other partner ever... \\
\hline & 1. Insulted you or made you feel bad about yourself? \\
\hline & 2. Belittled or humiliated you in front of other people? \\
\hline & $\begin{array}{l}\text { 3. Done things to scare or intimidate you on purpose (e.g. by the way he looked at you, by yelling and } \\
\text { smashing things)? }\end{array}$ \\
\hline & 4. Verbally threatened to hurt you or someone you care about? \\
\hline
\end{tabular}


approach was used to define prevalence of the different forms of abuse - controlling behaviour, emotional abuse and economic abuse.

Physical violence was considered severe if a participant reported having been hit, kicked, chocked or threatened with a weapon; and less severe if they reported having been pushed or slapped. For emotional abuse, economic abuse and controlling behaviours, severity was defined by the number of yes responses to the component questions of each abuse experienced by participant (Table 1).

We summarised the prevalence (with corresponding 95\% confidence intervals (CI)) of each type of violent and abusive act experienced, overall and by severity. We also summarised the prevalence of current violent and abusive acts for each stratum of the following sociodemographic variables: women's age, education, marital status, number of children, monthly earnings and overall socio-economic status; and male partner's age and education. We used structural equation modelling [19] to generate a summary socio-economic status indicator from 19 variables collected in the questionnaire. Symptoms of poor mental health were assessed by using SRQ-20 cutoff point of $7 / 8$ (yes to 8 or more questions is a case, 7 or less is a non-case). The associations between symptoms of poor mental health and different types of violence and abuses were explored by cross tabulations and logistic regression models. We summarised the associations firstly in terms of crude odds ratios and corresponding 95\% CIs, and secondly after controlling for age, socio-economic status, violence and abuses. Analyses were done using Stata version 13.1 software (StataCorp, College Station, TX, USA).

\section{Results}

Between September 2014 and June 2015, 66 out of 110 microfinance loan groups approached were recruited into the trial. Of the 1154 women in the 66 groups who received information about the trial, 1049 provided consent to join the study. Baseline interviews were conducted among 1021 women who were available at the time of the survey and reported to have ever been in a relationship. Women's age ranged from 19 to 70 years, with a median age of 39 years (interquartile range [IQR] 33-46), and $28.7 \%$ were less than 35 years of age. Most participants were married or living with a man as if married (72.8\%), and had completed primary education (72.3\%).

\section{Prevalence of violence and different forms of abuses}

Table 2 presents the lifetime and current prevalence of each type of violent and abusive act. Overall, about $61 \%$ of women reported ever experiencing physical and/or sexual IPV (95\% CI: 58-64\%) and 27\% (95\% CI: 24-29\%) experienced it in the past 12 months. When examined separately, the prevalence of lifetime physical and sexual violence was 53 and 35\%, respectively. The prevalence of physical and sexual violence during the past 12 months before the interviews was 19 and 17\%, respectively. Overall, most women who had experienced physical violence in their lifetime (68\%) or during the past 12 months (68\%) reported severe forms of violence.

Among other abuses, partner controlling behaviour was the most prevalent type of abuse with $82 \%$ experiencing it in their lifetime and $63 \%$ during the past 12 months. Other types of abuses were also common, with $34 \%$ of women reporting economic abuse and 39\% reporting emotional abuse during the past 12 months. Most women who reported economic (51\%) and emotional (54\%) abuse during the past 12 months had responded 'yes' to at least two different acts of abuse.

\section{Co-occurrence of past 12-month violence and abuse}

In Fig. 1, we present the co-occurrence (or overlaps) of reported violence and abuse during the past 12 months. Overall, there was considerable overlap between physical and sexual violence and the different forms of abuses, with only $276(27 \%)$ women not reporting any violence or abuse during the past 12 months. Among 271 women who reported physical and/or sexual violence by their current partners in the last 12 months, 94 (35\%) women experienced both physical and sexual violence; and almost all (98\%) report at least one form of abuse within the same time period. Out of 739 women who experienced at least one form of abuse, 200 (27.1\%) experienced all abuses (i.e. controlling behaviour, economic abuse and emotional abuse) in the last 12 months.

\section{Associations with socio-demographic characteristics}

In Tables 3 and 4 we present the associations between experience of violence and different forms of abuse in the past 12 months and selected socio-demographic characteristics. The prevalence of physical and/or sexual violence was highest among women below 30 years of age, and among those with primary education or less. Overall, the prevalence of violence decreased with increasing women's age and level of education. Similarly, the prevalence of violence decreased with increasing male partner's age and level of education. For controlling behaviour, higher prevalence rates were also found among younger women. Economic abuse showed no distinct patterns, although the prevalence of economic and emotional abuses was relatively low among women $\geq 50$ years and among those with post-secondary education. Women who were widowed and those without children below the age of 18 years were relatively less likely to experience violence or abuses when compared with other women. Women's monthly earnings and socio-economic status was not related to experience of violence or abuses. 
Table 2 Prevalence and severity of self-reported experiences of intimate partner violence and abuse among ever-partnered women $(N=1021)$ in Mwanza, Tanzania

\begin{tabular}{|c|c|c|c|c|c|c|c|c|}
\hline \multirow[b]{3}{*}{ Physical and/or sexual violence } & \multicolumn{4}{|c|}{ Lifetime experience } & \multicolumn{4}{|c|}{ Experienced during the 12 months before interview } \\
\hline & \multirow{2}{*}{$\frac{N}{621}$} & \multirow{2}{*}{$\begin{array}{l}\text { Percent } \\
60.8\end{array}$} & \multicolumn{2}{|c|}{$95 \% \mathrm{Cl}$} & \multirow{2}{*}{$\frac{N}{271}$} & \multirow{2}{*}{$\begin{array}{l}\text { Percent } \\
26.5\end{array}$} & \multicolumn{2}{|c|}{$95 \% \mathrm{Cl}$} \\
\hline & & & 57.8 & 63.8 & & & 23.9 & 29.4 \\
\hline \multicolumn{9}{|l|}{ Physical violence } \\
\hline Overalla $a$ & 541 & 53.0 & 49.9 & 56.1 & 194 & 19.0 & 16.6 & 21.5 \\
\hline Less severe ${ }^{c}$ & 175 & 17.1 & 14.9 & 19.6 & 63 & 6.2 & 4.8 & 7.8 \\
\hline Severe ${ }^{b}$ & 366 & 35.8 & 32.9 & 38.9 & 131 & 12.8 & 10.8 & 15.0 \\
\hline \multicolumn{9}{|l|}{ Sexual violence } \\
\hline Overall ${ }^{a}$ & 355 & 34.8 & 31.8 & 37.8 & 171 & 16.7 & 14.5 & 19.2 \\
\hline \multicolumn{9}{|l|}{ Controlling behaviour } \\
\hline Overall ${ }^{a}$ & 832 & 81.5 & 79.0 & 83.8 & 639 & 62.6 & 59.5 & 65.6 \\
\hline Yes to only 1 question & 256 & 25.1 & 22.4 & 27.9 & 250 & 24.5 & 21.9 & 27.2 \\
\hline Yes to $\geq 2$ questions & 576 & 56.4 & 53.3 & 59.5 & 389 & 38.1 & 35.1 & 41.2 \\
\hline \multicolumn{9}{|l|}{ Emotional abuse } \\
\hline Overall ${ }^{a}$ & 694 & 68.0 & 65.0 & 70.8 & 401 & 39.3 & 36.3 & 42.3 \\
\hline Yes to only 1 question & 267 & 26.2 & 23.5 & 29.0 & 184 & 18.0 & 15.7 & 20.5 \\
\hline Yes to $\geq 2$ questions & 427 & 41.8 & 38.8 & 44.9 & 217 & 21.3 & 18.8 & 23.9 \\
\hline \multicolumn{9}{|l|}{ Economic abuse } \\
\hline Overall ${ }^{\mathrm{a}}$ & 479 & 46.9 & 43.8 & 50.0 & 343 & 33.6 & 30.7 & 36.6 \\
\hline Yes to only 1 question & 206 & 20.2 & 17.8 & 22.8 & 167 & 16.4 & 14.1 & 18.8 \\
\hline Yes to $\geq 2$ questions & 273 & 26.7 & 24.0 & 29.6 & 176 & 17.2 & 15.0 & 19.7 \\
\hline
\end{tabular}

aFor each type of violence/abuse, the overall prevalence was defined as the \% of women who answered 'yes' to at least one question listed in Table $1 .{ }^{b}$ Women were classified as having experienced severe physical violence if they answered 'yes' to any of the last four physical violence questions listed in Table 1 (i.e. questions 3 to 6 ); and Cless severe if otherwise

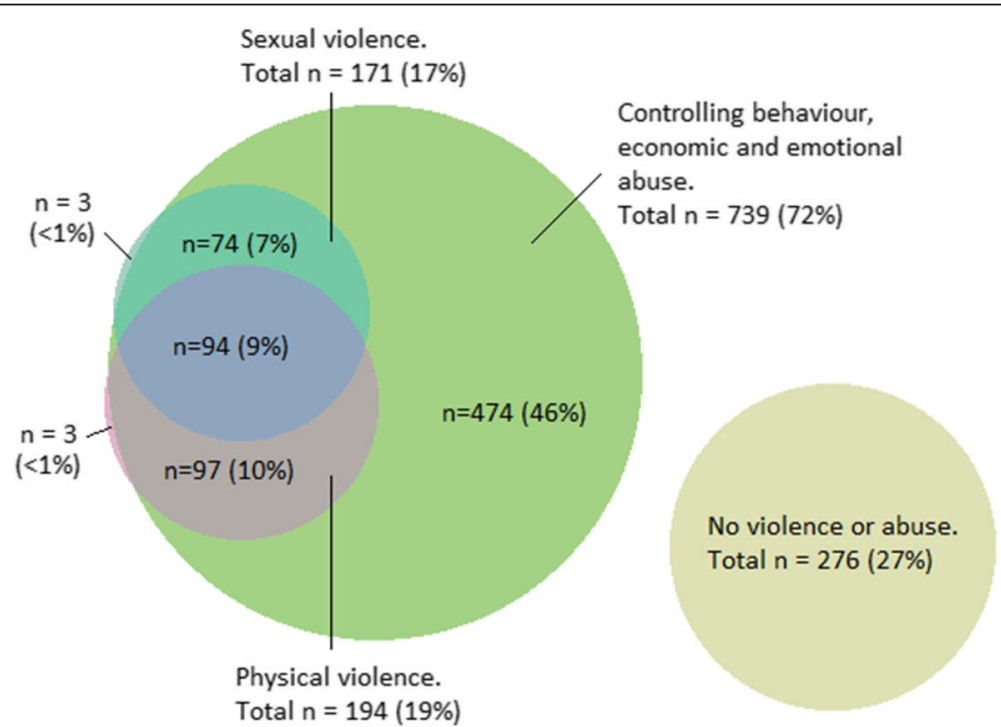

Fig. 1 Co-occurrence of self-reported experience of violence and abuse in the past 12 months $(n=1021)$ 
Table 3 The associations between experience of intimate partner violence during the past 12 months and socio-demographic characteristics among ever-partnered women in Mwanza, Tanzania

\begin{tabular}{|c|c|c|c|c|c|c|c|c|c|c|}
\hline & \multirow{3}{*}{$N$} & \multicolumn{3}{|c|}{ Physical and/or sexual violence } & \multicolumn{3}{|c|}{ Physical violence } & \multicolumn{3}{|c|}{ Sexual violence } \\
\hline & & \multirow[t]{2}{*}{ Percent } & \multicolumn{2}{|c|}{ Exact $95 \% \mathrm{Cl}$} & \multirow[t]{2}{*}{ Percent } & \multicolumn{2}{|c|}{ Exact $95 \% \mathrm{Cl}$} & \multirow[t]{2}{*}{ Percent } & \multicolumn{2}{|c|}{ Exact $95 \% \mathrm{Cl}$} \\
\hline & & & & & & & & & & \\
\hline Less than $30 \mathrm{yrs}$ & 143 & 42.0 & 33.8 & 50.5 & 31.5 & 24.0 & 39.8 & 25.2 & 18.3 & 33.1 \\
\hline $30-34$ yrs & 150 & 35.3 & 27.7 & 43.5 & 28.0 & 21.0 & 35.9 & 22.7 & 16.2 & 30.2 \\
\hline $35-39$ yrs & 234 & 28.2 & 22.5 & 34.4 & 20.9 & 15.9 & 26.7 & 17.9 & 13.3 & 23.5 \\
\hline $40-49$ yrs & 331 & 23.3 & 18.8 & 28.2 & 15.1 & 11.4 & 19.4 & 14.8 & 11.2 & 19.1 \\
\hline $50+y r s$ & 163 & 9.2 & 5.2 & 14.7 & 4.9 & 2.1 & 9.4 & 6.1 & 3.0 & 11.0 \\
\hline \multicolumn{11}{|l|}{ Level of education } \\
\hline No formal education & 59 & 27.1 & 16.4 & 40.3 & 18.6 & 9.7 & 30.9 & 16.9 & 8.4 & 29.0 \\
\hline Primary & 738 & 27.9 & 24.7 & 31.3 & 20.5 & 17.6 & 23.6 & 17.5 & 14.8 & 20.4 \\
\hline Secondary & 200 & 23.0 & 17.4 & 29.5 & 15.5 & 10.8 & 21.3 & 14.5 & 9.9 & 20.2 \\
\hline Post-secondary education & 24 & 12.5 & 2.7 & 32.4 & 4.2 & 0.1 & 21.1 & 12.5 & 2.7 & 32.4 \\
\hline \multicolumn{11}{|l|}{ Marital status } \\
\hline Married/living with man as if married & 743 & 30.6 & 27.3 & 34.0 & 22.6 & 19.6 & 25.8 & 19.2 & 16.5 & 22.3 \\
\hline Divorced/separated & 151 & 17.9 & 12.1 & 24.9 & 13.2 & 8.3 & 19.7 & 10.6 & 6.2 & 16.6 \\
\hline Widowed & 100 & 9.0 & 4.2 & 16.4 & 2.0 & 0.2 & 7.0 & 8.0 & 3.5 & 15.2 \\
\hline Never married & 27 & 29.6 & 13.8 & 50.2 & 14.8 & 4.2 & 33.7 & 14.8 & 4.2 & 33.7 \\
\hline \multicolumn{11}{|l|}{ Monthly earnings ${ }^{a}$} \\
\hline No personal earnings & 31 & 22.6 & 9.6 & 41.1 & 9.7 & 2.0 & 25.8 & 16.1 & 5.5 & 33.7 \\
\hline Less than USD 60 & 247 & 33.2 & 27.4 & 39.4 & 26.3 & 20.9 & 32.3 & 20.2 & 15.4 & 25.8 \\
\hline USD 60 to 179 & 303 & 26.1 & 21.2 & 31.4 & 18.8 & 14.6 & 23.7 & 16.5 & 12.5 & 21.2 \\
\hline USD 180 to 499 & 165 & 17.6 & 12.1 & 24.3 & 12.1 & 7.6 & 18.1 & 12.1 & 7.6 & 18.1 \\
\hline above USD 500 & 252 & 25.8 & 20.5 & 31.7 & 17.9 & 13.3 & 23.2 & 14.7 & 10.6 & 19.7 \\
\hline Don't know earnings & 23 & 39.1 & 19.7 & 61.5 & 17.4 & 5.0 & 38.8 & 39.1 & 19.7 & 61.5 \\
\hline \multicolumn{11}{|l|}{ Partner's age } \\
\hline Less than 30 yrs & 36 & 33.3 & 18.6 & 51.0 & 25.0 & 12.1 & 42.2 & 19.4 & 8.2 & 36.0 \\
\hline $30-34$ yrs & 80 & 47.5 & 36.2 & 59.0 & 38.8 & 28.1 & 50.3 & 27.5 & 18.1 & 38.6 \\
\hline $35-39$ yrs & 148 & 35.8 & 28.1 & 44.1 & 25.7 & 18.9 & 33.5 & 25.0 & 18.3 & 32.8 \\
\hline 40-49 yrs & 343 & 28.0 & 23.3 & 33.1 & 20.4 & 16.3 & 25.1 & 15.7 & 12.1 & 20.0 \\
\hline $50+y r s$ & 329 & 17.3 & 13.4 & 21.9 & 10.6 & 7.5 & 14.5 & 12.5 & 9.1 & 16.5 \\
\hline Don't know & 85 & 17.6 & 10.2 & 27.4 & 12.9 & 6.6 & 22.0 & 11.8 & 5.8 & 20.6 \\
\hline \multicolumn{11}{|l|}{ Partner's education } \\
\hline No formal education & 16 & 43.8 & 19.8 & 70.1 & 31.3 & 11.0 & 58.7 & 25.0 & 7.3 & 52.4 \\
\hline Primary & 567 & 29.5 & 25.7 & 33.4 & 22.4 & 19.0 & 26.1 & 18.9 & 15.7 & 22.3 \\
\hline Secondary & 316 & 24.1 & 19.4 & 29.2 & 15.8 & 12.0 & 20.3 & 14.6 & 10.9 & 18.9 \\
\hline Post-secondary education & 85 & 20.0 & 12.1 & 30.1 & 11.8 & 5.8 & 20.6 & 12.9 & 6.6 & 22.0 \\
\hline Don't know & 37 & 10.8 & 3.0 & 25.4 & 5.4 & 0.7 & 18.2 & 8.1 & 1.7 & 21.9 \\
\hline \multicolumn{11}{|c|}{ Respondent's number of children under 18 years } \\
\hline No children & 73 & 16.4 & 8.8 & 27.0 & 5.5 & 1.5 & 13.4 & 13.7 & 6.8 & 23.8 \\
\hline 1 Child & 151 & 23.2 & 16.7 & 30.7 & 12.6 & 7.7 & 19.0 & 15.2 & 9.9 & 22.0 \\
\hline 2 Children & 192 & 25.5 & 19.5 & 32.3 & 19.8 & 14.4 & 26.1 & 15.1 & 10.4 & 21.0 \\
\hline 3 Children & 225 & 31.6 & 25.5 & 38.1 & 23.1 & 17.8 & 29.2 & 20.9 & 15.8 & 26.8 \\
\hline
\end{tabular}


Table 3 The associations between experience of intimate partner violence during the past 12 months and socio-demographic characteristics among ever-partnered women in Mwanza, Tanzania (Continued)

\begin{tabular}{|c|c|c|c|c|c|c|c|c|c|c|}
\hline 4 Children & 170 & 25.9 & 19.5 & 33.1 & 18.8 & 13.2 & 25.5 & 14.1 & 9.3 & 20.3 \\
\hline 5 or more children & 210 & 28.6 & 22.6 & 35.2 & 23.3 & 17.8 & 29.6 & 18.1 & 13.1 & 24.0 \\
\hline \multicolumn{11}{|c|}{ Socio-economic status quintile ${ }^{b}$} \\
\hline $1^{\text {st }}$ & 192 & 29.7 & 23.3 & 36.7 & 21.9 & 16.2 & 28.4 & 20.3 & 14.9 & 26.7 \\
\hline $2^{\text {nd }}$ & 174 & 32.8 & 25.8 & 40.3 & 24.1 & 18.0 & 31.2 & 21.8 & 15.9 & 28.7 \\
\hline $3^{\text {rd }}$ & 209 & 19.6 & 14.5 & 25.7 & 12.9 & 8.7 & 18.2 & 13.9 & 9.5 & 19.3 \\
\hline $4^{\text {th }}$ & 198 & 26.8 & 20.7 & 33.5 & 20.7 & 15.3 & 27.0 & 13.1 & 8.8 & 18.6 \\
\hline $5^{\text {th }}$ & 194 & 24.2 & 18.4 & 30.9 & 18.0 & 12.9 & 24.2 & 12.9 & 8.5 & 18.4 \\
\hline Unknown & 54 & 29.6 & 18.0 & 43.6 & 13.0 & 5.4 & 24.9 & 25.9 & 15.0 & 39.7 \\
\hline
\end{tabular}

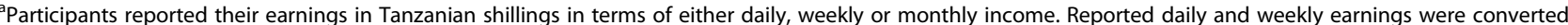
to monthly earnings on the assumption that each participant worked for 22 days per month. The conversion to US Dollars (USD) was based on the exchange rate at the time of data collection (1USD $=1,887$ Tanzanian shillings). ${ }^{\mathrm{b}} \mathrm{A}$ higher quintile indicates higher socio-economic status. The socio-economic status indicator was derived as a latent variable from 19 indicators collected in the questionnaire including education, earnings and household ownership of car, fridge, television and motorcycle

\section{Associations with symptoms of poor mental health} Overall, about $40 \%$ (95\% CI: 37-43\%) of women reported symptoms of poor mental health based on SRQ20 cut-off point of $7 / 8$. In Table 5 , we present the associations between experience of IPV and abuse during the past 12 months and symptoms of poor mental health. In general, the proportion of women with symptoms of poor mental health was relatively higher among women experiencing IPV and abuse. After we adjusted for age and socio-economic status, women who experienced physical violence $(\mathrm{OR}=1.8 ; 95 \% \mathrm{CI}: 1.3-2.7)$ and sexual violence $(\mathrm{OR}=2.8 ; 95 \% \mathrm{CI}: 1.9-4.1)$ were significantly more likely to report symptoms of poor mental health when compared to other women. Similarly, women reporting to have experienced emotional abuse $(\mathrm{OR}=1.5 ; 95 \% \mathrm{CI}$ : 1.1-2.2), and economic abuse ( $\mathrm{OR}=1.9 ; 95 \% \mathrm{CI}: 1.4-2.6)$ were more likely to report symptoms of poor mental health after we adjusted for age, socio-economic status and experience of violence.

\section{Discussion}

In this paper, we present baseline results from a study of women attending microfinance loan groups enrolled in the ongoing MAISHA study in Mwanza, Tanzania. We found a high prevalence of IPV, with $61 \%$ of women reporting ever experiencing physical and/or sexual IPV and $27 \%$ of women reporting it in the past 12 months. A substantial proportion of women reported severe physical violence which happened relatively frequently, suggesting that this is a common experience among women in this population. We also found a high prevalence of abuses, confirming that both violence and abuse from an intimate partner are common social, public health and human rights concerns among women in this study population.
The prevalence of sexual and/or physical violence in this population is consistent with previous studies conducted in Tanzania [3, 8, 18] and in other countries in sub-Saharan Africa [1]. To our knowledge, this is one of the first studies to examine the prevalence of emotional and economic abuse and controlling behaviour in a relationship in an African setting. A substantial proportion of women reported economic and emotional abuse in the last 12 months and almost two thirds of women reported experiencing at least one form of controlling behaviour during the same time period, suggesting this may constitute a form of normal behaviour in this Tanzanian population. We observed high rates of co-occurrence of reported IPV and abuses, with almost all women who reported experiencing physical and/or sexual violence in the last 12 months also reporting to have experienced one or more forms of abuse during the same time period. This high degree of overlap suggests that women in this population are more likely to experience both violence and multiple forms of abuse from their intimate partners. While more in-depth research is required to understand the impact of the different forms of abuse and controlling behaviour, our findings suggests that comprehensive violence prevention intervention programmes areneededto address IPV and more neglected forms of abuses [20].

We examined the associations between the prevalence of IPV and abuses in the last 12 months and sociodemographic characteristics. In general, IPV (and to some extent controlling behaviour) varied by sociodemographic characteristics, with much higher prevalence rates among younger women, women with young partners and women with less education. This is also in line with prior studies reporting women below the age of 25 having higher rates of violence than women aged 25 or older [21]. Potential reasons for this association are that relationships in younger age groups are more likely to be less 
Table 4 The associations between experience of intimate partner abuse during the past 12 months and socio-demographic characteristics among ever-partnered women in Mwanza, Tanzania

\begin{tabular}{|c|c|c|c|c|c|c|c|c|c|c|}
\hline & \multirow{3}{*}{$N$} & \multicolumn{3}{|c|}{ Controlling behaviour } & \multicolumn{3}{|c|}{ Emotional abuse } & \multicolumn{3}{|c|}{ Economic abuse } \\
\hline & & \multirow[t]{2}{*}{ Percent } & \multicolumn{2}{|c|}{ Exact $95 \% \mathrm{Cl}$} & \multirow[t]{2}{*}{ Percent } & \multicolumn{2}{|c|}{ Exact $95 \% \mathrm{Cl}$} & \multirow[t]{2}{*}{ Percent } & \multicolumn{2}{|c|}{ Exact $95 \% \mathrm{Cl}$} \\
\hline & & & & & & & & & & \\
\hline Less than $30 \mathrm{yrs}$ & 143 & 76.9 & 69.1 & 83.6 & 48.3 & 39.8 & 56.8 & 33.6 & 25.9 & 41.9 \\
\hline $30-34$ yrs & 150 & 74.7 & 66.9 & 81.4 & 55.3 & 47.0 & 63.4 & 40.0 & 32.1 & 48.3 \\
\hline $35-39$ yrs & 234 & 67.5 & 61.1 & 73.5 & 40.2 & 33.8 & 46.8 & 35.9 & 29.8 & 42.4 \\
\hline $40-49$ yrs & 331 & 58.9 & 53.4 & 64.3 & 38.4 & 33.1 & 43.8 & 36.6 & 31.4 & 42.0 \\
\hline $50+y r s$ & 163 & 39.3 & 31.7 & 47.2 & 17.2 & 11.7 & 23.9 & 18.4 & 12.8 & 25.2 \\
\hline \multicolumn{11}{|l|}{ Level of education } \\
\hline No formal education & 59 & 61.0 & 47.4 & 73.5 & 39.0 & 26.5 & 52.6 & 37.3 & 25.0 & 50.9 \\
\hline Primary & 738 & 60.8 & 57.2 & 64.4 & 40.7 & 37.1 & 44.3 & 34.6 & 31.1 & 38.1 \\
\hline Secondary & 200 & 69.5 & 62.6 & 75.8 & 36.0 & 29.4 & 43.1 & 30.0 & 23.7 & 36.9 \\
\hline Post-secondary education & 24 & 62.5 & 40.6 & 81.2 & 25.0 & 9.8 & 46.7 & 25.0 & 9.8 & 46.7 \\
\hline \multicolumn{11}{|l|}{ Marital status } \\
\hline Married/living with man as if married & 743 & 70.5 & 67.1 & 73.8 & 46.3 & 42.7 & 50.0 & 36.6 & 33.1 & 40.2 \\
\hline Divorced/separated & 151 & 47.7 & 39.5 & 56.0 & 24.5 & 17.9 & 32.2 & 28.5 & 21.4 & 36.4 \\
\hline Widowed & 100 & 26.0 & 17.7 & 35.7 & 11.0 & 5.6 & 18.8 & 19.0 & 11.8 & 28.1 \\
\hline Never married & 27 & 63.0 & 42.4 & 80.6 & 33.3 & 16.5 & 54.0 & 33.3 & 16.5 & 54.0 \\
\hline \multicolumn{11}{|l|}{ Monthly earnings ${ }^{a}$} \\
\hline No personal earnings & 31 & 77.4 & 58.9 & 90.4 & 48.4 & 30.2 & 66.9 & 35.5 & 19.2 & 54.6 \\
\hline Less than USD 60 & 247 & 59.1 & 52.7 & 65.3 & 44.1 & 37.8 & 50.6 & 35.6 & 29.7 & 41.9 \\
\hline USD 60 to 179 & 303 & 58.7 & 53.0 & 64.3 & 36.6 & 31.2 & 42.3 & 37.3 & 31.8 & 43.0 \\
\hline USD 180 to 499 & 165 & 63.6 & 55.8 & 71.0 & 37.6 & 30.2 & 45.4 & 26.1 & 19.5 & 33.5 \\
\hline above USD 500 & 252 & 66.3 & 60.1 & 72.1 & 36.9 & 30.9 & 43.2 & 30.2 & 24.6 & 36.2 \\
\hline Don't know earnings & 23 & 82.6 & 61.2 & 95.0 & 47.8 & 26.8 & 69.4 & 52.2 & 30.6 & 73.2 \\
\hline \multicolumn{11}{|l|}{ Partner's age } \\
\hline Less than 30 yrs & 36 & 66.7 & 49.0 & 81.4 & 47.2 & 30.4 & 64.5 & 22.2 & 10.1 & 39.2 \\
\hline $30-34$ yrs & 80 & 80.0 & 69.6 & 88.1 & 51.2 & 39.8 & 62.6 & 26.3 & 17.0 & 37.3 \\
\hline $35-39$ yrs & 148 & 75.7 & 67.9 & 82.3 & 48.0 & 39.7 & 56.3 & 39.2 & 31.3 & 47.5 \\
\hline $40-49$ yrs & 343 & 65.3 & 60.0 & 70.3 & 42.3 & 37.0 & 47.7 & 38.2 & 33.0 & 43.6 \\
\hline $50+y r s$ & 329 & 55.0 & 49.5 & 60.5 & 31.6 & 26.6 & 36.9 & 30.1 & 25.2 & 35.4 \\
\hline Don't know & 85 & 40.0 & 29.5 & 51.2 & 27.1 & 18.0 & 37.8 & 30.6 & 21.0 & 41.5 \\
\hline \multicolumn{11}{|l|}{ Partner's education } \\
\hline No formal education & 16 & 56.3 & 29.9 & 80.2 & 43.8 & 19.8 & 70.1 & 50.0 & 24.7 & 75.3 \\
\hline Primary & 567 & 60.7 & 56.5 & 64.7 & 41.6 & 37.5 & 45.8 & 33.3 & 29.5 & 37.4 \\
\hline Secondary & 316 & 65.5 & 60.0 & 70.7 & 39.6 & 34.1 & 45.2 & 34.8 & 29.6 & 40.3 \\
\hline Post-secondary education & 85 & 70.6 & 59.7 & 80.0 & 30.6 & 21.0 & 41.5 & 28.2 & 19.0 & 39.0 \\
\hline Don't know & 37 & 51.4 & 34.4 & 68.1 & 18.9 & 8.0 & 35.2 & 32.4 & 18.0 & 49.8 \\
\hline \multicolumn{11}{|c|}{ Respondent's number of children under 18 years } \\
\hline No children & 73 & 47.9 & 36.1 & 60.0 & 28.8 & 18.8 & 40.6 & 27.4 & 17.6 & 39.1 \\
\hline 1 Child & 151 & 57.6 & 49.3 & 65.6 & 34.4 & 26.9 & 42.6 & 29.1 & 22.0 & 37.1 \\
\hline 2 Children & 192 & 62.0 & 54.7 & 68.9 & 39.1 & 32.1 & 46.3 & 33.3 & 26.7 & 40.5 \\
\hline 3 Children & 225 & 64.4 & 57.8 & 70.7 & 36.4 & 30.2 & 43.1 & 37.3 & 31.0 & 44.0 \\
\hline
\end{tabular}


Table 4 The associations between experience of intimate partner abuse during the past 12 months and socio-demographic characteristics among ever-partnered women in Mwanza, Tanzania (Continued)

\begin{tabular}{lcccccccccc}
\hline $\begin{array}{l}\text { 4 Children } \\
\text { 5 or more children }\end{array}$ & 170 & 63.5 & 55.8 & 70.8 & 43.5 & 36.0 & 51.3 & 34.1 & 27.0 & 41.8 \\
$\begin{array}{l}\text { Socio-economic status quintile b } \\
1^{\text {st }}\end{array}$ & 210 & 69.0 & 62.3 & 75.2 & 46.2 & 39.3 & 53.2 & 34.8 & 28.3 & 41.6 \\
$2^{\text {nd }}$ & 192 & 57.3 & 50.0 & 64.4 & 42.2 & 35.1 & 49.5 & 29.7 & 23.3 & 36.7 \\
$3^{\text {rd }}$ & 174 & 63.2 & 55.6 & 70.4 & 44.8 & 37.3 & 52.5 & 33.9 & 26.9 & 41.5 \\
4 th & 209 & 64.1 & 57.2 & 70.6 & 34.9 & 28.5 & 41.8 & 33.5 & 27.1 & 40.3 \\
5th & 198 & 62.1 & 55.0 & 68.9 & 37.4 & 30.6 & 44.5 & 31.8 & 25.4 & 38.8 \\
Unknown & 194 & 61.3 & 54.1 & 68.2 & 35.6 & 28.8 & 42.7 & 36.6 & 29.8 & 43.8 \\
\hline
\end{tabular}

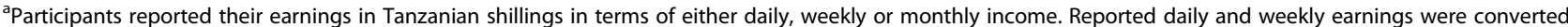
to monthly earnings on the assumption that each participant worked for 22 days per month. The conversion to US Dollars (USD) was based on the exchange rate at the time of data collection (1USD = 1,887 Tanzanian shillings). ${ }^{\mathrm{b}} \mathrm{A}$ higher quintile indicates higher socio-economic status. The socio-economic status indicator was derived as a latent variable from 19 indicators collected in the questionnaire including education, earnings and household ownership of car, fridge, television and motorcycle

stable, and to be associated with early pregnancy and higher levels of financial stress [22]. It is also possible that the levels of recall and social desirability bias is relatively lower among young women and therefore the likelihood of reporting IPV is higher in this population [23]. We observed relatively lower prevalence of IPV and abuses among women who were widowed and those without children below the age of 18 years. This is likely to be related to other factors, such as age, that are related to IPV in this population. Surprisingly, women's monthly earnings and socio-economic status were not found to be related to experiences of violence or abuses. This finding warrants further investigation in order to examine the role of socioeconomic status as a risk factor for IPV and abuses.

We found that women who reported experiencing IPV during the past 12 months were more likely to report symptoms of poor mental health, and this association remained unchanged after we adjusted for age and socioeconomic status. This is consistent with findings from other studies [5, 24, 25]. We also found that economic and emotional abuses were significantly associated with symptoms of poor mental health. These cross-sectional

Table 5 The associations between experience of intimate partner violence and abuse during the past 12 months and symptoms of poor mental health among ever-partnered women in Mwanza, Tanzania

\begin{tabular}{|c|c|c|c|c|c|c|c|c|c|c|}
\hline & $N$ & $\begin{array}{l}\text { Poor mental } \\
\text { health status } \\
n(\%)\end{array}$ & Odds ratio & \multicolumn{2}{|c|}{$95 \% \mathrm{Cl}$} & $P$ & $\begin{array}{l}\text { Adjusted odds } \\
\text { ratio }(A O R)^{a}\end{array}$ & \multicolumn{2}{|c|}{$95 \% \mathrm{Cl}$} & $P$ \\
\hline \multicolumn{11}{|l|}{ Physical violence } \\
\hline Experienced in past 12 months & 194 & $113(58.2)$ & 2.40 & 1.74 & 3.32 & $<0.001$ & 1.84 & 1.27 & 2.65 & 0.001 \\
\hline No Experience in past 12 months & 827 & $299(36.2)$ & 1 & & & & 1 & & & \\
\hline \multicolumn{11}{|l|}{ Sexual violence } \\
\hline Experienced in past 12 months & 171 & $110(64.3)$ & 3.34 & 2.34 & 4.78 & $<0.001$ & 2.76 & 1.86 & 4.09 & $<0.001$ \\
\hline No Experience in past 12 months & 850 & $302(35.5)$ & 1 & & & & 1 & & & \\
\hline \multicolumn{11}{|l|}{ Controlling behaviour } \\
\hline Experienced in past 12 months & 639 & $277(43.3)$ & 1.37 & 1.05 & 1.78 & 0.022 & 0.97 & 0.71 & 1.31 & 0.832 \\
\hline No Experience in past 12 months & 382 & $135(35.3)$ & 1 & & & & 1 & & & \\
\hline \multicolumn{11}{|l|}{ Economic abuse } \\
\hline Experienced in past 12 months & 343 & $194(56.6)$ & 2.71 & 2.06 & 3.57 & $<0.001$ & 1.86 & 1.35 & 2.57 & $<0.001$ \\
\hline No Experience in past 12 months & 678 & $218(32.2)$ & 1 & & & & 1 & & & \\
\hline \multicolumn{11}{|l|}{ Emotional abuse } \\
\hline Experienced in past 12 months & 401 & $213(53.1)$ & 2.40 & 1.84 & 3.13 & $<0.001$ & 1.53 & 1.09 & 2.15 & 0.015 \\
\hline No Experience in past 12 months & 620 & $199(32.1)$ & 1 & & & & 1 & & & \\
\hline
\end{tabular}

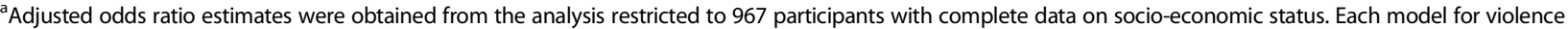
was adjusted for age, socio-economic status, and other violence. Each model for abuse was adjusted for age, socio-economic status, violence and other abuses 
findings suggest a strong association between IPV/abuses and symptoms of poor mental health, although it is not possible to confirm a causal link between them. Women who report symptoms of poor mental health may be more likely to experience violence [5], suggesting that poor mental health may be a risk factor for IPV. It is also possible that experience of severe and prolonged IPV may lead to poor mental health and other adverse health outcomes, as previously reported in prospective studies [26-28].

The high prevalence of IPV and abuses and its strong links with symptoms of poor mental health underline the importance of developing and testing appropriate interventions. As part of the MAISHA study, we are conducting a cluster randomised controlled trial to assess the impact of microfinance combined with gender training for women on participants' experience of physical and/or sexual IPV, as well as other gender-empowerment, economic, and health related outcomes in Mwanza, Tanzania. We have enrolled 1049 women receiving group-based microfinance loans and successfully delivered 10 sessions of gender training to women randomised to the intervention arm of the trial. The impact of the intervention will be assessed through a face-to-face interview during a followup survey to be conducted in 2017, approximately 29-30 months after randomisation.

The findings of this cross-sectional survey need to be considered in view of several limitations. Firstly, reporting of IPV may be prone to under-reporting due to social desirability or shame as women are commonly stigmatized and blamed for the abuse they receive. Several measures were implemented to minimise this problem, including training of interviewers to adhere to high ethical standards, and closely following the WHO guidelines on researching violence against women [29]. Secondly, the study was conducted among a sample of women receiving microfinance loans living in Mwanza, Tanzania's second largest city. It may therefore not be representative of the whole of Tanzania. However, this does not affect the validity of the findings presented, especially since the prevalence rates are comparable to previous studies. Thirdly, we analysed cross-sectional data collected at baseline, and this does not allow any inferences to be made regarding causality and temporality with respect to the socio-demographic factors and health outcomes assessed. Lastly, women's mental health status was assessed through self-report of symptoms and does not represent a clinical diagnosis.

\section{Conclusions}

In conclusion, these findings show that violence by an intimate partner is a major problem among women in Tanzania. We also found high levels of economic and emotional abuse and very high levels of controlling behaviour, with high rates of co-occurrence of reported IPV and abuses. The prevalence of IPV and abuses varied by socio-demographic characteristics, showing much higher prevalence rates among younger women, women with young partners and less educated women. The high prevalence of IPV and abuses and its strong links with symptoms of poor mental health underline the urgent need for developing and testing appropriate interventions in settings like Tanzania to tackle both violence and abusive behaviours among intimate partners. As part of the ongoing MAISHA study, we aim to assess the impact of microfinance combined with gender training for women on physical and/or sexual IPV in NW Tanzania.

\section{Acknowledgements}

We wish to thank all study participants for their time and commitment to the study.

\section{Funding}

MAISHA is supported by the STRIVE Research Programme Consortium funded by UK Aid from the Department for International Development (DFID) and another donor, who wishes to remain anonymous. The views expressed in this paper do not necessarily reflect the Department's official policies.

The funding bodies have had no role in the design of the study, the conduct, analysis and interpretation of data, or in writing the manuscript.

\section{Availability of data and materials}

Datasets analysed in this paper are part of a large MAISHA study. Because this study is still ongoing, datasets are not publicly available at this point. At the conclusion of our main study analyses data will be made available upon request and in accordance with NIMR and LSHTM regulations.

\section{Authors' contributions}

CW, SK and SL designed the study and led the grant application, and obtained ethics approvals from NIMR and LSHTM. SH, SK, and GM provided methodological input and oversaw the conduct of the study and management of the research teams. GM and SL provided support for the social science aspects of the study. $\mathrm{RH}, \mathrm{AM}, \mathrm{CH}$ and $\mathrm{HS}$ contributed in data management and analysis. All authors contributed to the manuscript preparation, and approved the final manuscript for submission.

\section{Competing interests}

The authors declare that they have no competing interests.

Consent for publication

Not applicable.

\section{Ethics approval and consent to participate}

The MAISHA study is being conducted following WHO recommendations on researching violence against women [29]. It has been approved by the Tanzanian National Health Research Ethics Committee of the National Institute for Medical Research (Ref: NIMR/HQ/R.8a/Vol. IX/1512), and the ethics committee of the London School of Hygiene \& Tropical Medicine (Ref: 11642). The study is implemented in close collaboration with local leaders and we have established a community liaison system to facilitate our team working with the communities where the study operates.

Written informed consent (witnessed by an independent witness for illiterate participants) was obtained from all participants before administering any study procedures.

\section{Author details}

${ }^{1}$ Mwanza Intervention Trials Unit, PO Box 11936, Mwanza, Tanzania.

${ }^{2}$ Department of Infectious Diseases Epidemiology, London School of Hygiene \& Tropical Medicine, Keppel Street, London WC1E 7HT, UK. ${ }^{3}$ Department of Global Health and Development, London School of Hygiene \& Tropical 
Medicine, Keppel Street, London WC1E 7HT, UK. ${ }^{4}$ National Institute for Medical Research, Isamilo Road, Mwanza, Tanzania.

\section{Received: 20 September 2016 Accepted: 7 February 2017} Published online: 14 February 2017

\section{References}

1. Devries KM, Mak JY, García-Moreno C, Petzold M, Child JC, Falder G, et al. The global prevalence of intimate partner violence against women. Science. 2013;340:1527-28.

2. Stöckl H, Devries K, Rotstein A, Abrahams N, Campbell J, Watts C, et al. The global prevalence of intimate partner homicide: a systematic review. Lancet. 2013:382:859-65.

3. National Bureau of Statistics (NBS) [Tanzania] and ICF Macro. Tanzania Demographic and Health Survey 2010. Dar es Salaam: NBS and ICF Macro; 2011.

4. Mulawa M, Kajula LJ, Yamanis TJ, Balvanz P, Kilonzo MN, Maman S. Perpetration and Victimization of Intimate Partner Violence Among Young Men and Women in Dar es Salaam, Tanzania. J Interpers Violence. 2016;12:126

5. Ellsberg $\mathrm{M}$, Jansen $\mathrm{HA}$, Heise L, Watts $\mathrm{CH}$, Garcia-Moreno $\mathrm{C}$. Intimate partner violence and women's physical and mental health in the WHO multi-country study on women's health and domestic violence: an observational study. Lancet. 2008:371:1165-72.

6. Organization WH: Global and regional estimates of violence against women: prevalence and health effects of intimate partner violence and non-partner sexual violence: World Health Organization; 2013.

7. Dillon G, Hussain R, Loxton D, Rahman S. Mental and physical health and intimate partner violence against women: a review of the literature. Int J Fam Med. 2013;2013:313909. doi:10.1155/2013/313909.

8. Mahenge B, Likindikoki S, Stöckl H, Mbwambo J. Intimate partner violence during pregnancy and associated mental health symptoms among pregnant women in Tanzania: a cross-sectional study. BJOG. 2013;120:940-6.

9. Devries KM, Mak JY, Bacchus LJ, Child JC, Falder G, Petzold M, et al. Intimate partner violence and incident depressive symptoms and suicide attempts: a systematic review of longitudinal studies. PLoS Med. 2013;10(5):e1001439.

10. Carbone-López K, Kruttschnitt C, Macmillan R. Patterns of intimate partner violence and their associations with physical health, psychological distress, and substance use. Public Health Rep. 2006;121:382-92.

11. Krantz G, Nguyen DV. The role of controlling behaviour in intimate partner violence and its health effects: a population based study from rural Vietnam. BMC Public Health. 2009:9:143. doi:10.1186/1471-2458-9-143.

12. Garcia-Moreno C. Dilemmas and opportunities for an appropriate healthservice response to violence against women. Lancet. 2002;359:1509-14.

13. Pronyk PM, Hargreaves JR, Kim JC, Morison LA, Phetla G, Watts C, et al. Effect of a structural intervention for the prevention of intimate-partner violence and HIV in rural South Africa: a cluster randomised trial. Lancet. 2006;368:1973-83.

14. Abramsky T, Devries K, Kiss L, Nakuti J, Kyegombe N, Starmann E, et al. Findings from the SASA! Study: a cluster randomized controlled trial to assess the impact of a community mobilization intervention to prevent violence against women and reduce HIV risk in Kampala. Uganda BMC Med. 2014:12:122. doi:10.1186/s12916-014-0122-5.

15. Ramsay J, Carter Y, Davidson L, Dunne D, Eldridge S, Feder G, et al. Advocacy interventions to reduce or eliminate violence and promote the physical and psychosocial well-being of women who experience intimate partner abuse. Cochrane Database Syst Rev. 2009;3:CD005043. doi:10.1002/14651858.

16. WHO. A user's guide to the self-reporting questionnaire (SRQ). Geneva: World Health Organization; 1994.

17. Harpham T, Reichenheim M, Oser R, Thomas E, Hamid N, Jaswal S, et al Measuring mental health in a cost-effective manner. Health Policy Plan. 2003:18:344-9.

18. Garcia-Moreno C, Jansen H, Ellsberg M, Heise L, Watts C. Prevalence of intimate partner violence: findings from the WHO multi-country study on women's health and domestic violence. Lancet. 2006;368:1260-9.

19. Muthén BO. Beyond SEM: General latent variable modeling. Behaviormetrika. 2002;29(1):81-117.

20. Jewkes R. Emotional abuse: a neglected dimension of partner violence. Lancet. 2010;376:851-2.

21. Stöckl H, March L, Pallitto C, Garcia-Moreno C. Intimate partner violence among adolescents and young women: prevalence and associated factors in nine countries: a cross-sectional study. BMC Public Health. 2014;14:751. doi:10.1186/1471-2458-14-751.

22. Renner LM, Whitney SD. Risk factors for unidirectional and bidirectional intimate partner violence among young adults. Child Abuse Negl. 2012;36:40-52

23. Stöckl H, Watts C, Penhale B. Intimate partner violence against older women in Germany prevalence and associated factors. J Interpers Violence. 2012;27:2545-64

24. Trevillion K, Oram S, Feder G, Howard LM. Experiences of domestic violence and mental disorders: a systematic review and meta-analysis. PLoS One. 2012:7(12):e51740.

25. Stöckl H, Penhale B. Intimate partner violence and its association with physical and mental health symptoms among older women in Germany. J Interpers Violence. 2015;30:3089-111.

26. Campbell JC. Health consequences of intimate partner violence. Lancet. 2002;359:1331-36

27. Romito P, MolzanTuran J, De Marchi M. The impact of current and past interpersonal violence on women's mental health. Soc Sci Med. 2005;60:1717-27.

28. Bonomi AE, Thompson RS, Anderson M, Reid RJ, Dimer JA, Carrell D, et al. Intimate partner violence and women's physical, mental, and social functioning. Am J Prev Med. 2006;30:458-66.

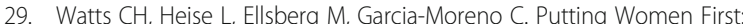
Ethical and safety recommendations for research on domestic violence against women. Geneva: World Health Organization; 1999.

\section{Submit your next manuscript to BioMed Central and we will help you at every step:}

- We accept pre-submission inquiries

- Our selector tool helps you to find the most relevant journal

- We provide round the clock customer support

- Convenient online submission

- Thorough peer review

- Inclusion in PubMed and all major indexing services

- Maximum visibility for your research

Submit your manuscript at www.biomedcentral.com/submit
Biomed Central 